\title{
A REVIEW OF STUDY OF STRENGTH AND DURABILITY ON CEMENT WITH ADDITION OF CERAMIC WASTE AND MICRO SILICA
}

\author{
Dharmesh Kumar Vishwakarma ${ }^{1}{ }^{\mathbb{W}}$, Prof. Harsh Gupta ${ }^{2}$ \\ ${ }^{1}$ Research scholar, Department of Civil Engineering, Jawaharlal Nehru College of Technology, Rewa \\ (M.P.), India \\ 2 Professor, Department of Civil Engineering, Jawaharlal Nehru College of Technology, Rewa (M.P.), \\ India
}

DOI: https://doi.org/10.29121/ijetmr.v8.i1.2021.861

Article Citation: Dharmesh Kumar Vishwakarma, and Prof. Harsh Gupta. (2021). A REVIEW OF STUDY OF STRENGTH AND DURABILITY ON CEMENT WITH ADDITION OF CERAMIC WASTE AND MICRO SILICA. International Journal of Engineering Technologies and Management Research, 8(1), 49-52. https://doi.org/10.29121/ijetmr.v8 .i1.2021.861

Published Date: 31 January 2021

Keywords:

Cement

Ceramic

Micro Silica

Strength and Durability

\begin{abstract}
Silica sand smaller than 70 microns can be used as a partial substitute for cement. This study partially demonstrated the properties of cement made of ceramic scrap and micro-silica instead of sand and cement. The effect of this recycled material was investigated by compressive strength tests and durability tests such as water absorption rate, absorption test and sulfate attack test.
\end{abstract}

\section{INTRODUCTION}

Cement is one of the most manufactured materials in the world. Due to the importance of cement as a building material and the geographical abundance of its main raw materials, cement limestone is produced in every country. Its widespread production is due to its relatively low cost and high density of cement. However, the production of Portland cement, the main component of concrete, emits significant carbon dioxide and greenhouse gases (GHGs).

Fume silica is a by-product of ferrosilicon and silicon metallic in electric arc furnaces. These by-products typically contain more than 0 percent silicon dioxide and may contain traces of other oxides depending on the load of the furnace and the silicon metal produced. 


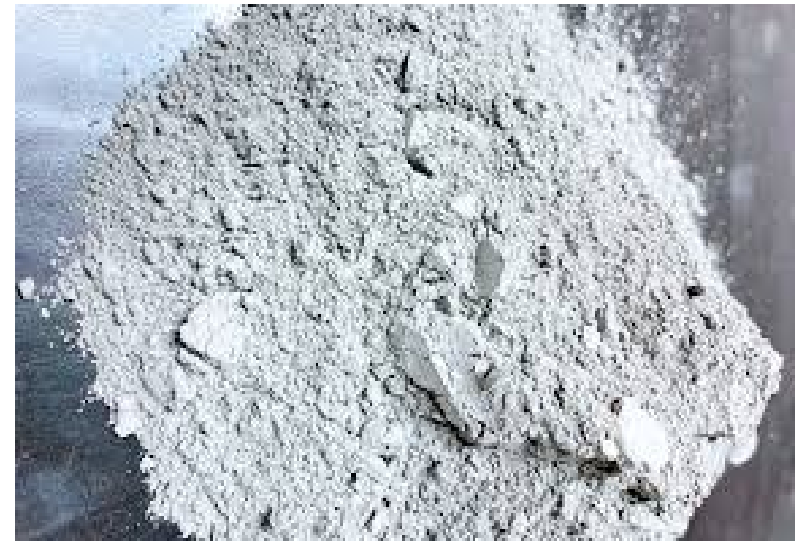

Figure 1: Cement

\section{MIXED DEVELOPMENT}

The main component in the production of high-quality concrete is the low-to-cement ratio. Concrete applicability (15 to $30 \%$ by weight of cement) requires a significant amount of silica ash for optimum applicability and relatively high-water content. When a large amount of water is added to the mixture, it dries or shrinks upon drying as time saving means saving money, try to reduce the mixing time. Various mixtures were developed for the development of blends that would form mixtures with desired properties. Combine pre-stored cement and silica. Add fume silica to the mixture to ensure proper wetting and good dispersion during mixing.

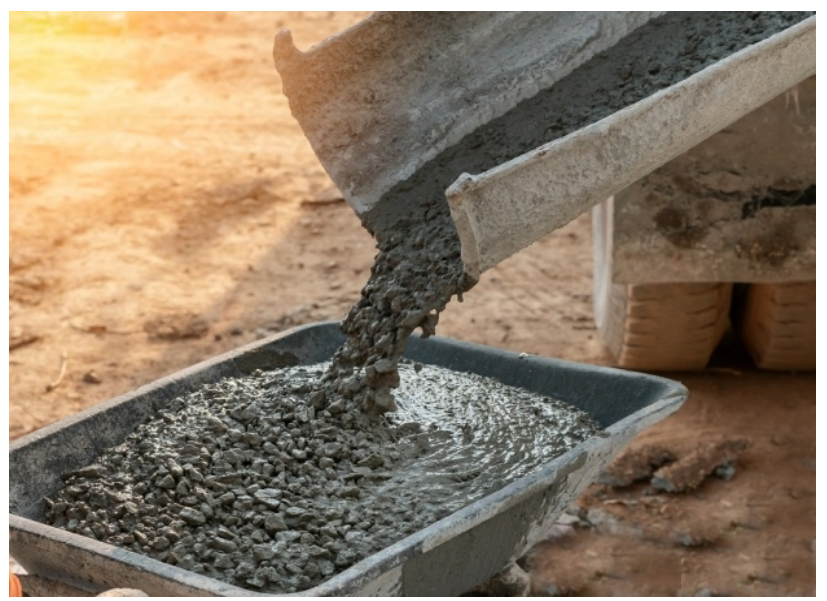

Figure 2: Cement and concrete work

\section{SOLID WORK}

Concrete work can be satisfying when you step back and look at a well-equipped construction project. But even concrete tasks can be frustrating for beginners who "sink" without adequate preparation. In the next tutorial I will discuss concrete work tips that will help you run DIY construction projects more smoothly for beginners.

A little vocabulary for the first sticker. Although "do" and "cement" are often used by do-it-yourself people, in reality, the difference between concrete and cement ("mortar" is also a part of "mix"). Basically, this is the actual material that makes up the building. Cement is just one component in concrete: it is a component that combines with other components (e.g., aggregate and sand). Therefore, while it is an important critical component of concrete, "cement" is not synonymous with "concrete". Usually, when people say they need to buy "cement" and go out on a DIY project, they really mean "concrete". 


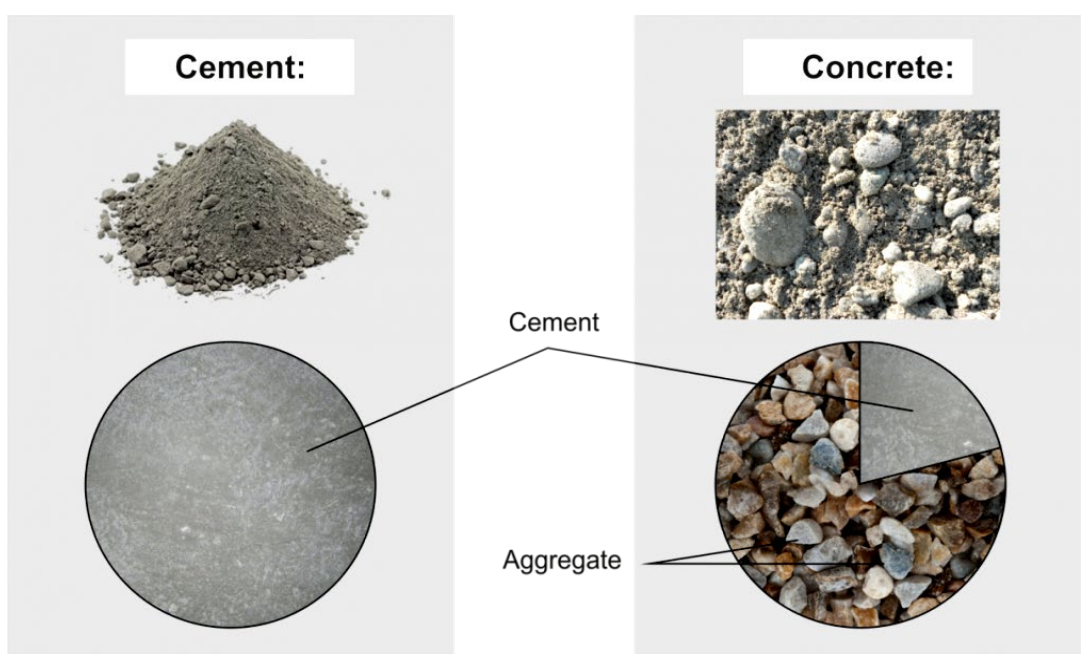

Figure 3: Cement, concrete and aggregate

\section{SILICA SAND}

Silica is a very fine material that is made entirely from silicon and oxygen, two abundant elements in the earth's crust. Silica is rigid, chemically heavy, and has a high melting point, which is due to the bond between the atoms. Silica sand is not flammable, combustible or explosive. It is not known to be toxic. This is not an environmental threat. Silica sand is insoluble in water. Silica sand should be dried and kept outside the component.

\section{CEMENT}

Common Portland Cement confirms the 53-grade DECCN brand used in the current work of BIS standards. Cement has been tested for various properties as per IS: 4031-1988 and found to meet the requirement as per IS: 12269-1987.

\section{CONCLUSIONS}

The concept of green concrete using complementary cement materials such as silica sand reduces the environmental impact of concrete. The use of these waste by-products as partial replacement of cement will further benefit the environment by reducing environmental pollution.

\section{SOURCES OF FUNDING}

This research received no specific grant from any funding agency in the public, commercial, or not-for-profit sectors.

\section{CONFLICT OF INTEREST}

The author have declared that no competing interests exist.

\section{ACKNOWLEDGMENT}

None. 
A Review of Study of Strength and Durability on Cement with Addition of Ceramic Waste and Micro Silica

\section{REFERENCES}

[1] M. S. Shetty, Concrete Technology\|, Year 2008

[2] Taiwan, Concrete International\|, 1995, vol-17, pp 71-76

[3] P. J. M. Monterio, Concrete: Microstructure, properties and Materials

[4] B. Mather, Concrete Year 2000, Revisited\|, ACI journal, vol-144, pp31-40, 1994. 